\title{
Johannes Bähr, Werner von Siemens 1816-1892. Eine
}

Biografie

Johann Boillat

\section{(2) OpenEdition}

\section{Journals}

Édition électronique

URL : http://journals.openedition.org/ifha/8720

DOI : $10.4000 /$ ifha. 8720

ISSN : 2198-8943

\section{Éditeur}

IFRA - Institut franco-allemand (sciences historiques et sociales)

\section{Référence électronique}

Johann Boillat, « Johannes Bähr, Werner von Siemens 1816-1892. Eine Biografie », Revue de l'IFHA [En ligne], Date de recension, mis en ligne le 02 novembre 2017, consulté le 24 septembre 2020. URL: http://journals.openedition.org/ifha/8720 ; DOI : https://doi.org/10.4000/ifha.8720

Ce document a été généré automatiquement le 24 septembre 2020

(CIFHA 


\section{Johannes Bähr, Werner von Siemens 1816-1892. Eine Biografie}

Johann Boillat

\section{RÉFÉRENCE}

Johannes Bähr, Werner von Siemens 1816-1892. Eine Biografie, München: C.H. Beck, 2016, 576 p., $29,95 €$ 
Si l'exercice de la biographie historique n'est jamais aisé, il peut devenir périlleux lorsqu'il a pour ambition de retracer la trajectoire d'un industriel à l'origine de la création d'un fleuron national. C'est pourtant ce qu'a entrepris avec succès le Prof. Dr. Johannes Bähr dans son ouvrage consacré à la vie de Werner von Siemens (1816-1892).

Ce travail monumental s'appuie sur l'analyse rigoureuse de deux types de sources. Il s'agit tout d'abord de documents de nature privée, conservés à Berlin (Geheimes Staatsarchiv Preussischer Kulturbesitz et Siemens Corporate Archives), à Francfort-sur-le-Main (Historisches Archiv der Deutschen Bank), à Brauschweig (Stadtarchiv Braunschweig) et à Goslar (Archiv der Siemens-Familienstiftung). Sur la

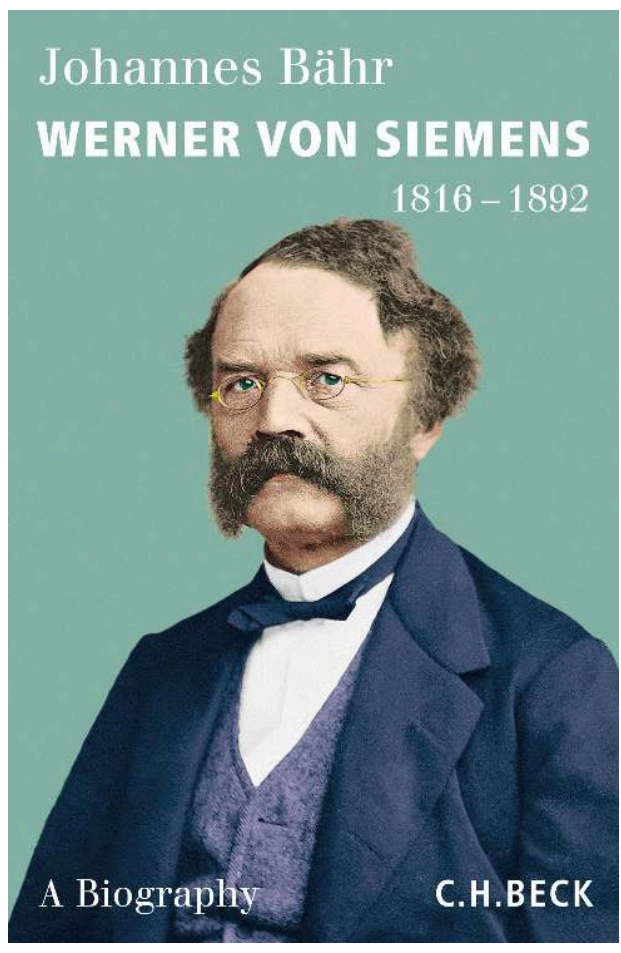
base de procès-verbaux, de rapports techniques, de correspondance commerciale et d'échanges épistolaires parfois intimes, ils ont permis de mettre en exergue les interrelations entre l'entrepreneur, ses bailleurs de fonds, les associations d'intérêts et les milieux politiques, militaires et scientifiques. Parallèlement, J. Bähr s'est attelé à la lourde tâche de recenser les rapports officiels, les articles techniques et d'autres contributions scientifiques rédigées ou éditées par Werner von Siemens luimême.

Ce traitement scientifique de sources hétérogènes permet de renouveler la perception d'un des acteurs majeurs du développement industriel allemand au XIX ${ }^{\mathrm{e}}$ siècle. En éclairant la chronologie des événements ayant permis à l'atelier familial de devenir un puissant conglomérat, l'historien nous aide à comprendre comment celui-ci s'est hissé à la pointe de la technologie, grâce à l'internalisation de structures de recherches et de développement centralisées à Berlin, performantes et autonomes, et grâce à l'établissement d'un réseau exclusif de filiales permettant d'inonder les marchés internationaux en produits et en équipements stratégiques pour l'industrie des machines, l'industrie électrique, l'industrie des télécommunications, l'industrie médicale et l'industrie des transports (von Weiher et Goetzeler 1981, Takenaka 1996, Donzé 2013, Donzé 2014, Donzé 2015).

Tout au long des douze chapitres équilibrés, l'auteur évite deux pièges classiques, pour le plus grand bonheur du lecteur. Tout d'abord, et même s'il retrace le développement du petit Werner de la cellule familiale à la multinationale, J. Bähr parvient à restituer la trajectoire de l'intéressé sans verser dans le réflexe hagiographique typique de la publication anniversaire. Ensuite, et peut-être surtout, l'historien fait surgir la question de la dépendance du Konzern face à la supériorité américaine, notamment avec le procédé Edison, et retrace son affranchissement progressif par la mise en place d'un lobbysme dans le contexte du développement embryonnaire des politiques nationales 
de protection intellectuelle (Beltran, Chauveau et Galvez-Behar 2001; Galvez-Behar 2011).

Ainsi, la présentation de la vie et de l'œuvre de Werner von Siemens se distingue des précédentes tentatives dans la mesure où l'on est loin de l'image d'un self-made man voguant immanquablement de succès en succès et surmontant les épreuves à force de travail et d'abnégation (Feldenkirchen 1996; Feldenkirchen et Eberhard 2005 ; Michel, 1997 et Cadi 2010). Cette publication s'inscrit donc dans la lignée des biographies définitives et vient admirablement compléter la contribution consacrée à Carl von Siemens (Lutz 2013), aux mêmes éditions.

INDEX

Index chronologique : Époque contemporaine

Thèmes : Histoire sociale, Histoire économique

\section{AUTEURS}

JOHANN BOILLAT

Forschungsinstitut für Wissenschafts- und Technikgeschichte

Deutsches Museum

München 